\title{
Simple, Efficient, and Modular Syntheses of Polyene Natural Products via Iterative Cross-Coupling
}

\author{
Suk Joong Lee, Kaitlyn C. Gray, James S. Paek, and Martin D. Burke* \\ Roger Adams Lab, Department of Chemistry, University of Illinois at Urbana-Champaign, Urbana, \\ Illinois 61801
}

\begin{abstract}
This communication describes the discovery of air-stable and highly versatile B-protected haloalkenylboronic acid building blocks for iterative cross-coupling. These reagents enable the total synthesis of polyene natural products with extraordinary levels of simplicity, efficiency, and modularity. Specifically, all-trans-retinal, $\beta$-parinaric acid, and one-half the amphotericin B macrolide skeleton were prepared using only the Suzuki-Miyaura reaction in an iterative manner to bring together collections of simple and readily-accessible building blocks. In contrast to their boronic acid counterparts, the intermediate polyenylboronate esters are remarkably stable (to both column purification and storage), which is critical to their successful utilization. Moreover, the reactive boronic acids can be cleanly liberated using very mild aqueous base. These advances have enabled preparation of the longest polyene ever synthesized using the SM reaction. We additionally report, to the best of our knowledge, the first triply metal selective ( $\mathrm{Zn}$ vs. Sn and B) cross-coupling reaction, the first selective cross-coupling with a differentially-ligated diboron reagent, and the first cross-couplings between polyenylchlorides and vinylboronic acids. Collectively, these new building blocks and methods can dramatically improve the way polyene natural products and their derivatives are synthesized in the laboratory.
\end{abstract}

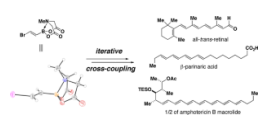

\begin{abstract}
Most biologically active small molecules exert their effects via the perturbation of macromolecular targets. ${ }^{1}$ There are a few, however, that operate via higher-order mechanisms that lie outside this paradigm. The class of "polyene natural products" 2 is particularly rich with examples. Perhaps most notable is the antifungal heptaene macrolide amphotericin B (AmB, 1, Figure 1A), which self-assembles into a membrane-spanning channel complex with functional properties reminiscent of protein-based ion channels. ${ }^{3,4}$ Other polyenes are known to provide structural support for cell membranes, ${ }^{5}$ transduce solar energy into mechanical energy, ${ }^{6}$ serve as pigments for efficient light harvesting ${ }^{7}$ and/or species-specific coloration, ${ }^{8}$ act as fluorescent probes, ${ }^{9}$ and/or quench reactive oxygen species. ${ }^{10}$ The existence of these natural prototypes suggests that the potential for small molecules to perform useful functions in living systems likely extends far beyond that which is currently utilized. Unfettered synthetic access to these compounds and their derivatives is paramount for realizing this potential.
\end{abstract}

The synthesis of polyenes is made challenging by the sensitivity of conjugated double bond frameworks to light, oxygen, and many common synthetic reagents, especially protic and

\footnotetext{
*burke@scs.uiuc.edu .

Supporting Information Available: Procedures, spectral data, and spectra for all new compounds. X-ray crystallographic data (cif) for $\mathbf{B B}_{1}$ and 14. This information is available free of charge via the Internet at http://pubs.acs.org/.
} 
Lewis acids. Controlling stereochemistry during the formation of each double bond is also a critical issue. Syntheses based on palladium-mediated cross-coupling are attractive due to the mild, non-acidic, and stereospecific nature of these methods. ${ }^{11,12}$ Among these, the Suzuki-Miyaura (SM) reaction ${ }^{11 \mathrm{~d}}$ stands out due to its use of non-toxic boronic acid reagents and well-precedented functional group compatibility. However, polyenylboronic acids are notoriously unstable ${ }^{13}$ which precludes their general utilization. We recently developed a simple and flexible strategy for making small molecules involving the iterative cross-coupling of haloboronic acids protected as the corresponding pyramidalized $\mathrm{N}$ methyliminodiacetic acid (MIDA, 2) adducts. ${ }^{14}$ We herein report a novel collection of Bprotected haloalkenylboronic acid building blocks $\mathbf{B B}_{1}-\mathbf{B B}_{3}$ (Fig. 1B) that are strikingly stable to purification and storage, and highly selective towards a wide range of crosscoupling reactions. This stability is maintained in the resulting polyenyl MIDA-boronate ester intermediates, thereby enabling the simple, efficient, and modular construction of a variety of polyene natural products with higher-order functions.

The first targeted building block containing a single double bond $\left(\mathbf{B B}_{1}\right)$ was prepared via complexation of $(E)$-(2-bromoethenyl)dibromoborane $\mathbf{3}^{15}$ with MIDA (Scheme 1). This reaction was performed on $>20 \mathrm{~g}$ scale $(75 \mathrm{mmol})$ to yield the desired bifunctional olefin $\mathbf{B B}_{1}$ as a crystalline, free-flowing solid. X-ray analysis confirmed unambiguously the pyramidalized nature of the boron center. ${ }^{16}$ Remarkably, this densely-functionalized alkene is stable to silica gel chromatography and storage for at least 1.5 years on the benchtop under air.

Moreover, $\mathbf{B B}_{1}$ was found to be a very versatile cross-coupling partner (Scheme 1). For example, the $\mathrm{sp}^{3}$-hybridized boronate ester terminus was inert to Buchwald's anhydrous SM conditions ${ }^{17}$ thus enabling a selective cross-coupling with $(E)$-styrenylboronic acid $\mathbf{4}$ to provide dienyl boronate $\mathbf{6}$ in excellent yield. ${ }^{18,19}$ A Stille coupling between $\mathbf{B B}_{1}$ and vinyl stannane $\mathbf{7}$ was similarly efficient, yielding butadienyl boronate $\mathbf{8}$. Moreover, a Heck coupling with methyl acrylate $\mathbf{9}$ yielded the unsaturated methyl ester $\mathbf{1 0}$ as a single regioand stereoisomer.

A series of novel bis-metallated lynchpin-type reagents ${ }^{12}$ were also created. Specifically, Sonogashira coupling between $\mathbf{B B}_{1}$ and TMS-acetylene $\mathbf{1 1}$ generated hetero-bis-metallated enyne 12. Although Miyaura borylations ${ }^{20}$ with $(E)$-1,2-disubstituted vinyl halides are challenging, ${ }^{20 \mathrm{~b}}$ we found that ligand $\mathbf{5} \mathbf{a}^{20 \mathrm{c}}$ enabled the smooth conversion of $\mathbf{B B}_{1}$ into the novel bis-borylated olefin $\mathbf{1 4}$ (an X-ray structure of $\mathbf{1 4}$ is shown in Scheme 2). Like $\mathbf{B B}_{1}, \mathbf{1 4}$ is a column- and shelf-stable crystalline solid (stable under air for at least 1.5 years). Finally, Negishi cross-coupling between $\mathbf{B B}_{1}$ and the hetero-bis-metallated vinylzinc reagent $\mathbf{1 5}^{12 \mathrm{~d}}$ yielded lynchpin 16 in a novel triply-metal selective (Zn vs. Sn and B) reaction.

With the goal of developing robust, shelf-stable building blocks for polyene synthesis, we designed di- and trienyl halides $\mathbf{B B}_{2}$ and $\mathbf{B B}_{3}$ as the corresponding vinyl chlorides. ${ }^{21} \mathrm{~A}$ direct route to the targeted dienylchloride $\mathbf{B B}_{2}$ was envisioned via a concomitant metal- and halogen-selective SM cross-coupling between bisborylated olefin 14 and (E)-1-chloro-2iodoethylene $\mathbf{1 7}^{22}$ (Scheme 2). Due to the absence of a boron p-orbital, ${ }^{14 a}$ we hypothesized that the $\mathrm{sp}^{3}$-hybridized MIDA-boronate terminus of $\mathbf{1 4}$ would be unreactive relative to the $\mathrm{sp}^{2}$-hybridized pinacol boronic ester. In fact, as shown in Scheme 2, single crystal X-ray diffraction analysis confirmed the distinct hybridization states of the two boron termini of 14, and a halogen- and boron-selective cross-coupling with 17 yielded the targeted bifunctional diene $\mathbf{B B}_{2}$ as a column- and shelf-stable crystalline solid. This novel type of selective cross-coupling with a differentially-ligated diboron reagent may prove to be generally useful. ${ }^{23}$ 
The final targeted polyene building block containing three double bonds $\left(\mathbf{B B}_{3}\right)$, was prepared via another metal- ${ }^{12 \mathrm{i}}$ and halogen-selective cross-coupling between bis- $^{-}$ functionalized reagents $\mathbf{1 6}$ and $\mathbf{1 7}$ (Scheme 3). Despite containing a potentially sensitive triene moiety, $\mathbf{B B}_{3}$ is also both column- and shelf-stable.

Although the strength of $\mathrm{C}-\mathrm{Cl}$ bonds can make the building blocks that contain them quite stable, it also makes these reagents relatively unreactive towards cross-coupling. ${ }^{24}$ Moreover, the structural and stereochemical labilities of polyene frameworks preclude the use of forcing conditions. As a result, to the best of our knowledge, SM cross-coupling between a polyenylchloride and a vinylboronic acid has never been previously reported. ${ }^{25}$ To overcome this challenge, we extensively surveyed a variety of catalysts with different base and solvent combinations for cross-coupling between $\mathbf{B B}_{3}$ and model substrate $(E)$-1pentenylboronic acid 18. Ultimately, it was determined that the use of $\mathrm{Pd}(\mathrm{OAc})_{2} /$ phosphine $\mathbf{5} \mathbf{b}^{17}$ and $\mathrm{Cs}_{2} \mathrm{CO}_{3}$ in THF at $45{ }^{\circ} \mathrm{C}$ gave good yields of tetraenyl MIDA boronate $\mathbf{1 9}$ (Scheme 3). ${ }^{18}$

With the three targeted building blocks $\mathbf{B B}_{1}-\mathbf{B B}_{3}$ in hand and their potential for selective cross-couplings verified, we explored the utility of these new reagents in the context of total syntheses of polyene natural products that perform higher-order functions. For example, the carotenoid all-trans-retinal (22) has the ability to transduce solar energy into mechanical energy and is a critical functional component of the light-driven proton pump found in Halobacteria and the photoreception machinery utilized by most animals. ${ }^{6}$ Structure/ function studies with this natural product have unique potential to enable the understanding of these phenomena at the molecular level. ${ }^{6 c}$

B-protected haloalkenylboronic acid $\mathbf{B B}_{1}$ was utilized in a highly modular three-step synthesis of retinal from known starting materials (Scheme 4). ${ }^{26}$ Specifically, the selective SM coupling between $\mathbf{B B}_{1}$ and trienylboronic acid $\mathbf{1 9}^{26 \mathrm{~d}}$ yielded the tetraenyl MIDA boronate 20. Notably, although the instability of $\mathbf{1 9}$ precludes its isolation in concentrated form, ${ }^{26 \mathrm{~d}}$ tetraenyl MIDA boronate $\mathbf{2 0}$ was isolated via column chromatography as a crystalline solid that can be stored refrigerated for at least one month without decomposition.

A key feature of the MIDA protective group is its capacity for removal under mild, aqueous basic conditions. ${ }^{14 a}$ Given the sensitive nature of polyenylboronic acids, ${ }^{13}$ the Bdeprotection of intermediate $\mathbf{2 0}$ presented a rigorous test for this methodology. In the event, this deprotection proceeded smoothly and subsequent SM coupling of the resulting solution of crude boronic acid with the known $\beta$-bromo enal $\mathbf{2 1}^{27}$ succeeded in generating the targeted all-trans-retinal 22.

Another interesting polyene, $\beta$-parinaric acid 26, has been used for more than three decades as a fluorescent probe for membrane properties. ${ }^{9,28}$ In addition, related tetraenoic acids demonstrate remarkable aggregation behaviors ${ }^{29}$ including the formation of antipodal chiral aggregates from a single enantiomer. ${ }^{29 b}$ The utility of $\mathbf{2 6}$ and/or its analogs would benefit from more efficient and modular synthetic access to this class of compounds. ${ }^{30}$

In this vein, the B-protected chlorodienylboronic acid $\mathbf{B B}_{2}$ was employed in a modular, three-step synthesis of $\beta$-parinaric acid from readily-available starting materials (Scheme 5). Specifically, using a modification of the newly identified conditions for polyenylchloride cross-coupling, a selective pairing between the bifunctional dienylchloride $\mathbf{B B}_{2}$ and $(E)$-1butenylboronic acid $\mathbf{2 3}^{16}$ yielded the column-stable all-trans trienyl boronate $\mathbf{2 4}$. Bdeprotection of $\mathbf{2 4}$ was achieved under mild aqueous basic conditions, and subsequent crosscoupling with vinyl iodide $\mathbf{2 5}{ }^{16}$ yielded $\beta$-parinaric acid $\mathbf{2 6}$ as a fluorescent solid. 
As a final example, the polyene macrolide $\mathrm{AmB}^{3}$ (Fig. 1A) represents a potential prototype for small molecules that replicate the functions of protein-based ion channels. ${ }^{31}$ An efficient and flexible total synthesis of AmB stands to enable the first systematic dissection of the structure/function relationships that underlie this small molecule-based ion channel activity. ${ }^{4}$

In contrast to strategies based on lynchpin-type reagents, ${ }^{12}$ the cross-coupling of B-protected haloboronic acids has the theoretical capacity for limitless iteration. ${ }^{14}$ Harnessing this potential, the synthesis of one-half of the AmB macrolide skeleton via recursive SM coupling has been achieved (Scheme 6). Specifically, boronic acid $\mathbf{1 8}$ was joined with $\mathbf{B B}_{1}$ to generate dienylboronate $\mathbf{2 7}$. A subsequent series of B-deprotection and coupling of the resulting dienylboronic acid with trienylchloride $\mathbf{B B}_{\mathbf{3}}$ yielded column-stable pentaenyl MIDA boronate 28. Finally, taking advantage of the recent discovery in our laboratories that MIDA boronates can be used directly as surrogates for boronic acids under aqueous SM conditions, ${ }^{32}$ a one-pot B-deprotection and cross-coupling with dienylchloride $29^{16}$ yielded one-half of the amphotericin B skeleton 30. To the best of our knowledge, this is the longest polyene ever synthesized using the SM reaction. This pathway may ultimately provide the foundation for an efficient and flexible total synthesis of this notoriously challenging natural product. $^{33}$

As demonstrated herein, B-protected haloalkenylboronic acid building blocks such as $\mathbf{B B}_{\mathbf{1}^{-}}$ $\mathbf{B B}_{3}$ have potential for broad utility in the context of total syntheses of polyene natural products. The iterative cross-coupling approach is particularly well-suited for making these types of structures due to the ubiquity of $\mathrm{Csp}^{2}-\mathrm{Csp}^{2}$ bonds, the mild and stereospecific nature of the coupling methods, and the exceptional stability of the intermediate polyenyl MIDA boronate esters. This simple, efficient, and modular strategy stands to enable the more effective study and widespread utilization of this class of highly functional small molecules.

\section{Supplementary Material}

Refer to Web version on PubMed Central for supplementary material.

\section{Acknowledgments}

Dedicated to Prof. P. Beak with deepest respect and gratitude for his invaluable advocacy and mentorship, and for partial funding for S.J.L. We also gratefully acknowledge A.D. Melhado for preliminary studies towards 29, the $\mathrm{NIH}$ (GM080436), the Dreyfus Foundation, and UIUC for funding, Sigma-Aldrich for a gift of $\mathrm{Pd}\left(\mathrm{PPh}_{3}\right)_{4}$, BristolMyers Squibb and Xenobe for gifts of AmB, and S. Wilson for X-ray analysis.

\section{REFERENCES}

(1). Corey, EJ.; Czakó, B.; Kürti, L. Molecules and Medicine. Wiley; New Jersey: 2007.

(2). Thirsk C, Whiting A. J. Chem. Soc. Perkin Trans. 2002; 1:999-1023.

(3). (a) Ermishkin LN, Kasumov Kh.M. Potzeluyev VM. Nature. 1976; 262:698-699. [PubMed: 958440] (b) Hartsel SD, Hatch C, Ayenew W. J. Liposome Res. 1993; 3:377-408.

(4). Palacios DS, Anderson TM, Burke MD. J. Am. Chem. Soc. 2007; 129:13804-13805. [PubMed: 17956100]

(5). Rohmer M, Bouvier P, Ourisson G. Proc. Natl. Acad. Sci. USA. 1979; 76:847-851. [PubMed: 284408]

(6). (a) Luecke H, Schobert B, Richter H-T, Cartailler J-P, Lanyi JK. Science. 1999; 286:255-260. [PubMed: 10514362] (b) Kobayashi T, Saito T, Ohtani H. Nature. 2001; 414:531-534. [PubMed: 11734850] (c) Zhong Q, Ruhman S, Ottolenghi M, Sheves M, Friedman N, Atkinson GH, Delaney JK. J. Am. Chem. Soc. 1996; 118:12828-12829. 
(7). (a) Cerullo G, Polli D, Lanzani G, De Silvestri S, Hashimoto H, Cogdell RJ. Science. 2002; 298:2395-2398. [PubMed: 12493917] (b) Hoffman E, Wrench PM, Sharples FP, Hiller RG, Welte W, Diederichs K. Science. 1996; 272:1788-1791. [PubMed: 8650577]

(8). Vershinin A. BioFactors. 1999; 10:99-104. [PubMed: 10609869]

(9). Sklar LA, Hudson BS, Simoni RD. Proc. Nat. Acad. Sci. USA. 1975; 72:1649-1653. [PubMed: 1057769]

(10). Burton GW, Ingold KU. Science. 1984; 224:569-573. [PubMed: 6710156]

(11). (a) Diederich, F.; Stang, PJ., editors. Metal-Catalyzed Cross-coupling Reactions. Wiley-VCH; Weinheim: 1998. (b) Negishi, E-I., editor. Handbook of Organopalladium Chemistry for Organic Synthesis. Vol. Vol. 1. John Wiley \& Sons; New York: 2002. (c) Nicolaou KC, Bulger PG, Sarlah D. Angew. Chem. Int. Ed. 2005; 44:4442-4489.(d) Miyaura N, Suzuki A. Chem. Rev. 1995; 95:2457-2483.(e) Fürstner A, Nevado C, Waser M, Tremblay M, Chevrier C, Teply F, Aïssa C, Moulin E, Müller O. J. Am. Chem. Soc. 2007; 129:9150-9161. [PubMed: 17602484]

(12). Representative examples of bis-metallated reagents for polyene synthesis: (a) Corey EJ, Wollenberg RH. J. Org. Chem. 1975; 40:3788-3789. (b) Lhermitte F, Carboni B. Synlett. 1996:377-379. (c) Lipshutz BH, Lindsley C. J. Am. Chem. Soc. 1997; 119:4555-4556. (d) Pihko PM, Koskinen AMP. Synlett. 1999; 12:1966-1968. (e) Babudri F, Farinola GM, Fiandanese V, Mazzone L, Naso F. Tetrahedron. 1998; 54:1085-1094. (f) Murakami M, Matsuda T, Itami K, Ashida S, Terayama M. Synthesis. 2004; 9:1522-1526. (g) Denmark SE, Tymonko SA. J. Am. Chem. Soc. 2005; 127:8004-8005. [PubMed: 15926811] (h) Lipshutz BH, Clososki GC, Chrisman W, Chung DW, Ball DB, Howell J. Org. Lett. 2005; 7:4561-4564. [PubMed: 16209479] (i) Coleman RS, Walczak MC. Org. Lett. 2005; 7:2289-2291. [PubMed: 15901191] (j) Coleman RS, Lu X, Modolo I. J. Am. Chem. Soc. 2007; 129:3826-3827. [PubMed: 17358066]

(13). (a) Roush WR, Brown BB. J. Am. Chem. Soc. 1993; 115:2268-2278.(b) Torrado A, Iglesias B, López S, de Lera AR. Tetrahedron. 1995; 51:2435-2454.

(14). (a) Gillis EP, Burke MD. J. Am. Chem. Soc. 2007; 129:6716-6717. [PubMed: 17488084] (b) Noguchi H, Hojo K, Suginome M. J. Am. Chem. Soc. 2007; 129:758-759. [PubMed: 17243801]

(15). Hyuga S, Chiba Y, Yamashina N, Hara S, Suzuki A. Chem. Lett. 1987:1757-1760.

(16). See Supporting Information for synthesis and characterization.

(17). Barder TE, Walker SD, Martinelli JR, Buchwald SL. J. Am. Chem. Soc. 2005; 127:4685-4696. [PubMed: 15796535]

(18). The same yield was observed whether or not this reaction was set up using a glove box.

(19). Dienyl boronate $\mathbf{6}$ was stable to storage for at least two weeks on the benchtop under air both as a solid and as a solution in DMSO- $d_{6}$.

(20). (a) Ishiyama T, Murata M, Miyaura N. J. Org. Chem. 1995; 60:7508-7510.(b) Takagi J, Takahashi K, Ishiyama T, Miyaura N. J. Am. Chem. Soc. 2002; 124:8001-8006. [PubMed: 12095344] (c) Billingsley KL, Barder TE, Buchwald SL. Angew. Chem. Int. Ed. 2007; 46:5359_ 5363.

(21). $\mathrm{Csp}^{2}-\mathrm{Cl}$ bonds tend to be much stronger than their $\mathrm{Br}$ and I counterparts, which we expect to impact favorably on the stability of polyenylhalide building blocks. For example, the bond dissociation energies for $\mathrm{Ph}-\mathrm{X}=96,81$, and $65 \mathrm{kcal} / \mathrm{mol}$ for $\mathrm{X}=\mathrm{Cl}, \mathrm{Br}$, and $\mathrm{I}$, respectively: Grushin VV, Alper H. Chem. Rev. 1994; 94:1047-1062.

(22). Negishi E, Okukado N, Lovich SF, Luo F-T. J. Org. Chem. 1984; 49:2629-2632.

(23). Steric-based selective couplings with bis-pinacolboronic esters are known: (a) Desurmont G, Klein R, Uhlenbrock S, Laloë E, Deloux L, Giolando DM, Kim YW, Pereira S, Srebnik M. Organometallics. 1996; 15:3323-3328. (b) Ishiyama T, Miyaura N. J. Organomet. Chem. 2000; 611:392-402.

(24). Littke AF, Fu GC. Angew. Chem. Int. Ed. 2002; 41:4176-4211.

(25). SM cross-couplings between vinylchlorides and vinylboronic acids are also extremely rare. For one example see: Organ MG, Cooper JT, Rogers LR, Soleymanzadeh F, Paul T. J. Org. Chem. 2000; 65:7959-7970. [PubMed: 11073604]

(26). Cross-coupling-based syntheses of retinoids: (a) Negishi E, Owczarczyk Z. Tetrahedron Lett. 1991; 32:6683-6686. (b) ref 13b. (c) Uenishi J, Kawahama R, Yonemitsu O, Wada A, Ito M. 
Angew. Chem. Int. Ed. 1998; 37:320-323. (d) Uenishi J, Matsui K, Wada A. Tetrahedron Lett. 2003; 44:3093-3096.

(27). Romo D, Rzasa RM, Shea HA, Park K, Langenhan JM, Sun L, Akhiezer A, Liu JO. J. Am. Chem. Soc. 1998; 120:12237-12254.

(28). Kuerschner L, Ejsing CS, Ekroos K, Schevchenko A, Anderson KI, Thiele C. Nature Methods. 2005; 2:39-45. [PubMed: 15782159]

(29). (a) Wang Y, Ma J, Cheon H-S, Kishi Y. Angew. Chem. Int. Ed. 2007; 46:1333-1336.(b) Ma J, Cheon H-S, Kishi Y. Org. Lett. 2007; 9:319-322. [PubMed: 17217294]

(30). Some prior syntheses of $\beta$-parinaric acid: (a) Kuklev DV, Smith WL. Chem. Phys. Lipids. 2004; 131:215-222. [PubMed: 15351273] (b) Goerger MM, Hudson BS. J. Org. Chem. 1988; 53:31483153. (c) Hayashi T, Oishi T. Chem. Lett. 1985:413-416.

(31). (a) El-Etri M, Cuppoletti J. Am. J. Physiol. Lung Cell. Mol. Physiol. 1996; 270:L386-L392.(b) Gao L, Broughman JR, Iwamoto T, Tomich JM, Vemglarik CJ, Forman HJ. Am. J. Physiol. Lung Cell. Mol. Physiol. 2001; 281:L24-L30. [PubMed: 11404241] (c) Jiang C, Lee ER, Lane MB, Xiao Y-F, Harris DJ, Cheng SH. Am. J. Physiol. Lung Cell. Mol. Physiol. 2001; 281:L1164-L1172. [PubMed: 11597908] (d) Sidorov V, Kotch FW, Kuebler JL, Lam Y-F, Davis JT. J. Am. Chem. Soc. 2003; 125:2840-2841. [PubMed: 12617627]

(32). Knapp DM, Gillis EP, Burke MD. Manuscript in preparation.

(33). (a) Nicolaou KC, Daines RA, Ogawa Y, Chakraborty TK. J. Am. Chem. Soc. 1988; 110:46964705. (b) Cereghetti DM, Carreira EM. Synthesis. 2006; 6:914-942. 
A

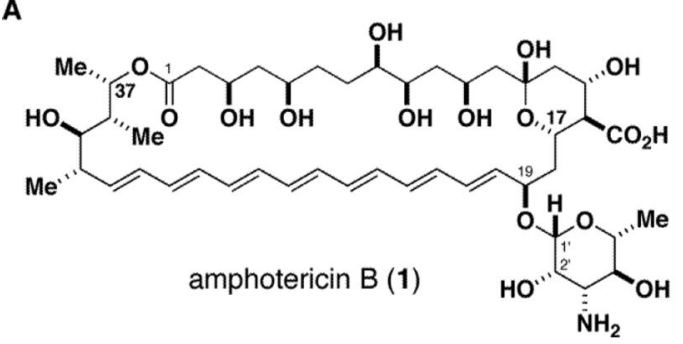

B

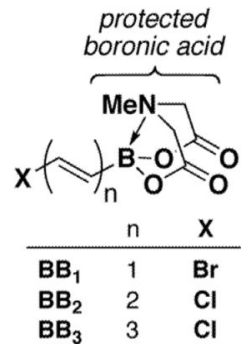

Figure 1.

A. The channel-forming natural product amphotericin B. B. A series of B-protected haloalkenylboronic acid building blocks for polyene synthesis. 


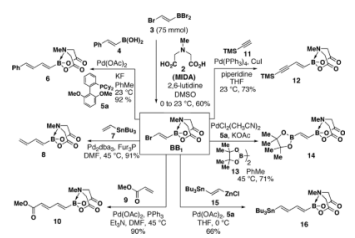

Scheme 1.

J Am Chem Soc. Author manuscript; available in PMC 2011 June 2. 


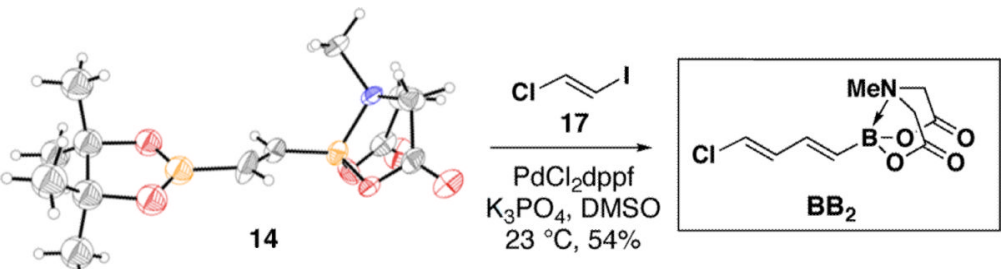

Scheme 2. 


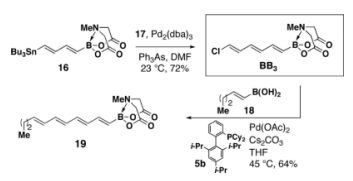

Scheme 3.

J Am Chem Soc. Author manuscript; available in PMC 2011 June 2. 


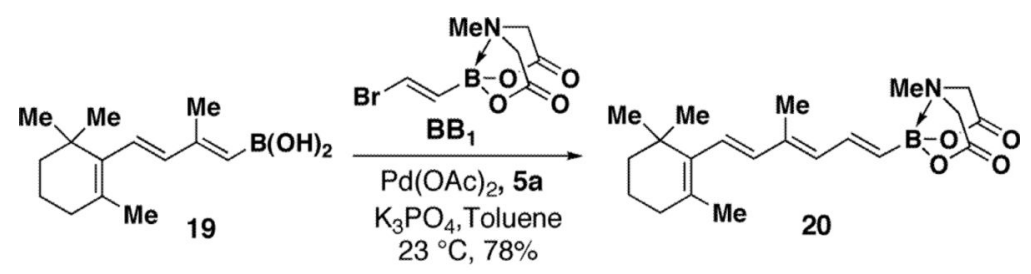

1. aq. $\mathrm{NaOH}, \mathrm{THF}, 23^{\circ} \mathrm{C}$
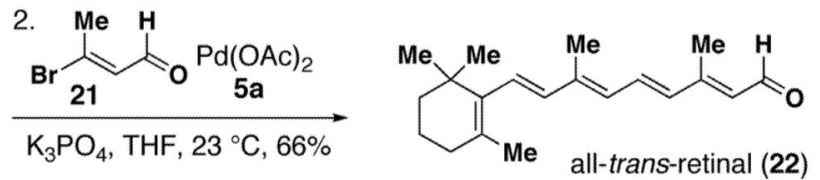

Scheme 4. 


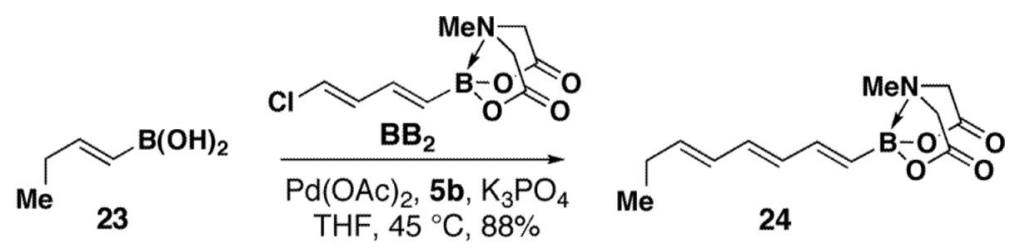

1. aq. $\mathrm{NaOH}, \mathrm{THF}, 23^{\circ} \mathrm{C}$

2. $\curvearrowright X_{25}^{7} \mathrm{CO}_{2} \mathrm{H}$

$\overrightarrow{\mathrm{Pd}(\mathrm{OAc})_{2}, 5 \mathbf{b} \text {, aq. } \mathrm{NaOH}} \mathrm{Me}$ THF, $23{ }^{\circ} \mathrm{C}, 86 \%$

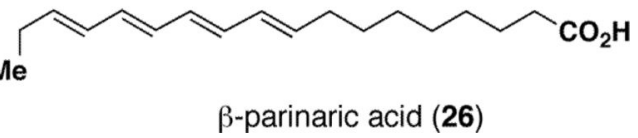

Scheme 5. 


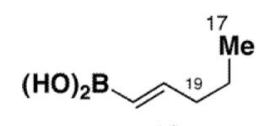

18
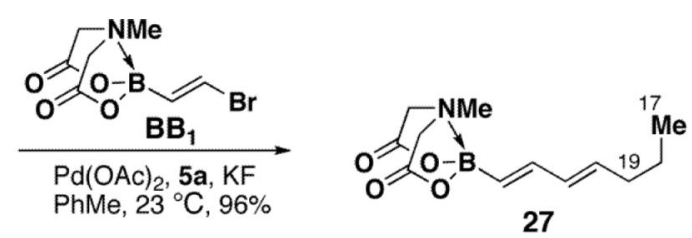
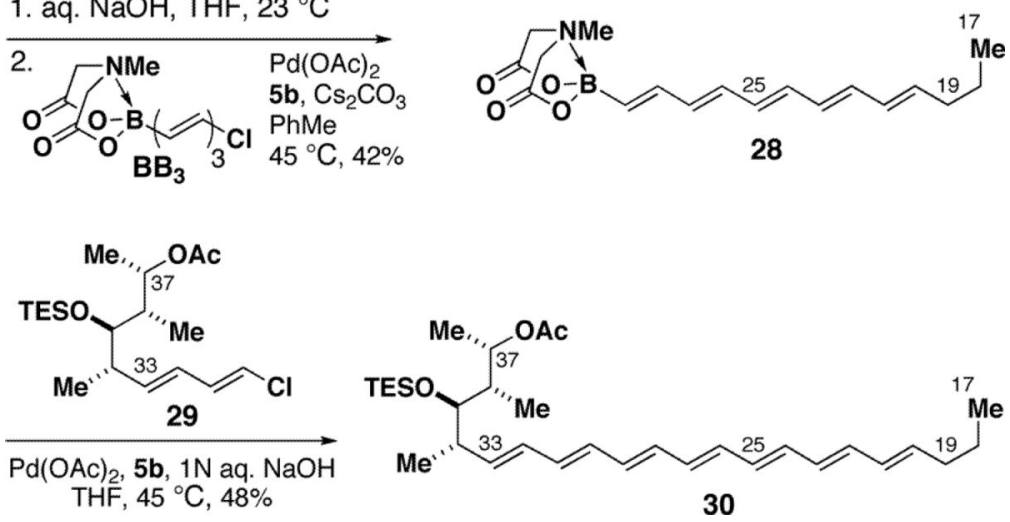

Scheme 6. 